\title{
Commercializing a radical innovation: probing the way to the market
}

This is an author self-archive version, this is not equal to the final published version

\author{
A paper submitted to Industrial Marketing Management \\ Special issue on Barriers and Consequences of Radical Innovations
}

Final article DOI:

https://doi.org/10.1016/j.indmarman.2014.08.004

\begin{abstract}
Authors:
Leena Aarikka-Stenroos and Tuula Lehtimäki

Contact information:

Leena Aarikka-Stenroos (corresponding author)

Department of Marketing and International Business

Turku School of Economics, University of Turku
\end{abstract}

Tuula Lehtimäki

Department of Marketing

Oulu Business School, University of Oulu 
Biographies:

Dr. Leena Aarikka-Stenroos is a Senior Researcher at the Department of Marketing and International Business, Turku School of Economics, University of Turku. Her research focuses on business marketing, knowledge intensive services, relationship initiations, the commercialization of innovations, and the role of networks in innovation and service businesses. Her articles have been published in, e.g. Industrial Marketing Management, Journal of Business Research, Journal of Business and Industrial Marketing, International Journal of Technology Marketing, and several international books.

Tuula Lehtimäki is a postdoctoral researcher at the Department of Marketing and International Business, Turku School of Economics, University of Turku. Her research interests include new product launches, commercialization, business models, and innovation management. She has been published in, e.g. Industrial Marketing Management and International Journal of Technology Marketing.

Acknowledgements: The authors gratefully acknowledge the contributions from the anonymous reviewers and the guest editors whose constructive advices improved the article. Thanks also to Professor Nicole Coviello, and the commentators and reviewers at the ISPIM 2012 conference for their inspiring comments on the early version of the article. We are also grateful to the Foundation of Economic Education and the Finnish Funding Agency for Technology and Innovation for supporting this research. 


\section{Research Highlights}

Firms face critical challenges in commercialization.

This study examines the commercialization of RIs as a process complicated by divergent challenges.

By analyzing six longitudinal cases, the study develops a dynamic process model for the commercialization of RIs.

The model includes three zones: strategic decision making, market creation/preparation, and sales creation/development.

Over the probing-like commercialization process, a firm faces six major challenges.

For managers, the results suggest diligence in the neglected market creation and preparation zone. 


\begin{abstract}
Needs, market structures, business models, and relationships concerning radical innovations (RIs) are unpredictable and, consequently, firms face critical challenges in commercialization. Therefore, this study examines the commercialization of RIs as a process complicated by divergent challenges. By drawing on the literature on innovation management, RIs, and the commercialization and adoption of innovations, and by analyzing six longitudinal cases, the study generates its contribution: a dynamic process model for the commercialization of RIs. The model captures the iterative and partially unpredictable commercialization process comprising transits back and forth between three main zones: strategic marketing decision making, market creation and preparation, and sales creation and development. Over this probing process, a firm faces major commercialization challenges: 1) choosing a feasible strategy in conditions of uncertainty, 2) understanding the benefits of innovation from the customer's perspective, 3) creating credibility, 4) acquiring support from stakeholders and the ecosystem, 5) overcoming adoption barriers, and 6) creating sales. For managers, the results suggest diligence in the neglected market creation and preparation zone instead of attempting rushed sales creation.
\end{abstract}

Keywords: commercialization; innovation process; innovation management; radical innovations; case study; technology marketing; probing 


\section{INTRODUCTION}

Success with a radical innovation (RI) does not often come directly and through wisely predetermined decisions but via a probing process. The technology and market uncertainties typical to RI make the whole innovation process a long-run entity that swings back and forth (Coviello \& Joseph 2012, O'Connor \& Rice 2013b) as firms need to probe how to manage the uncertainties (Lynn, et al. 1996, O'Connor, et al. 2008). Hence, the commercialization of a radically new product or service can also become cumbersome and prolonged; it is rare for a firm to achieve RI success with the first attempt (Costa, et al. 2004, Lynn et al. 1996). For example, in the iconic Post-it Notes case, it took ten years of struggle and refinement before the firm finally succeeded with the revolutionary and popular sticky notes (see Garud \& Karnøe 2001).

Commercialization conventionally refers to the moment of facing markets and disseminating the innovation (e.g., Crawford \& Di Benedetto 2006, Story, et al. 2011). It is a critical area of the innovation process (Chiesa \& Frattini 2011) and crucial to RI success and performance (Schilling 2005, Song \& Montoya-Weiss 1998). It is often the least well-managed area of the entire innovation process and, therefore, although being technically and functionally superior to competing offerings, most RIs fail (Chiesa \& Frattini 2011, Cooper 2011, Costa, et al. 2004). Even experienced innovator firms seem to blunder in commercialization (Chiesa \& Frattini 2011). Nevertheless, current research still tends to focus more on RI development (e.g., Golder, Shacham, \& Mitra 2009, Veryzer 2005) and the front end (e.g., Markham 2013, Reid \& de Brentani 2010 2012), rather than commercialization aspects, i.e., taking the envisioned and developed RI to market. Therefore, this study aims to analyze the commercialization of RIs as an evolving process over which a firm probes how to commercialize the focal product or service and overcome the critical challenges. We believe that this topic has both academic and managerial relevance as it facilitates understanding on how to improve RI success. RI refers here to a radically new product or service that changes behavior patterns in the target market (e.g., Chiesa \& Frattini 2011, Story, et 
al. 2011), and creates a line of business that is new to the firm and market (O'Connor 1998).

Commercialization means marketing an innovation with the aim of converting it into a profitmaking position in the marketplace; it entails both marketing strategy planning and subsequent implementation (e.g., Chiesa \& Frattini 2011, Costa et al. 2004). Commercialization also includes launch and market introduction (e.g., Crawford \& Di Benedetto 2008, Hitsch 2006).

Commercialization is often conceptualized as a separate late stage/phase of the innovation process comprising the front end or ideation, technical development, and commercialization (e.g., Koen, et al. 2001, O'Connor, et al. 2008, Story, et al. 2011). However, research has increasingly noted that many decisions and activities of the front end, technical development, and commercialization interact and evolve in parallel throughout the RI process (see Prebble, de Wall, \& de Groot 2008, Prenkert 2012). For example, visioning and early decisions concerning the market and concept made at the front end influence further activities and innovation success (Markham 2013, Reid \& de Brentani 2012). Hence, we perceive that commercialization and other activities of the innovation process are complementary, concurrent and mutually linked. The commercialization aspect assumingly is lighter at the beginning and grows along the innovation process. We also agree that the aim of commercialization is to disseminate the innovation. In this study, however, we propose that, in contrast to stage approaches, commercialization itself is a process.

We assume that the commercialization process is complicated and shaped by challenges that originate from multiple facets of innovativeness; namely, technology, customer behavior, and marketing (e.g., Costa, et al. 2004, McNally, et al. 2010, Story, et al. 2011). Multifaceted innovativeness induces divergent challenges as it generates adoption barriers among customers (Lettl 2007, O’Connor 1998, Rogers 1983) and other stakeholders (Aarikka-Stenroos \& Sandberg 2012, Woodside 1996), and pushes the firm to face unfamiliar product categories, competitors, distribution channels, and customers (Garcia \& Calantone 2002, Leifer, et al. 2001). Furthermore, one strategy assumingly does not fit throughout commercialization, since based on Moore (2002), after the initial 
introduction to a visionary early market, a firm needs to change its marketing strategy to conquer the conservative early majority market. Only then, typically, are RIs in a position to make a profit, after which commercialization is "sustained" (e.g., Jolly 1997). However, despite the criticality and extent of the challenges, few efforts to study commercialization-related challenges of RIs have been made (e.g., Chiesa \& Frattini 2011, McDermott \& O’Connor 2002), and have not thoroughly investigated the emergence of divergent challenges along the commercialization process. Thus, our first research question is: What are the key commercialization challenges in the commercialization process of RIs? By developing a classification of commercialization challenges, this study contributes much needed clarity on the specific challenges of RIs.

The second question concerns the essence of commercialization per se. Although research has suggested that the commercialization of RIs is more complicated than "just launch", requiring multiple activities and reassessments (Costa, et al. 2004, Lynn, et al. 1996, O’Connor \& Rice 2013b) and that unsuccessful novel products can later achieve success (e.g., Garud, Gehman, \& Kumaraswamy 2011, Harrison \& Waluszewski 2008), none of the extant investigations focus on the complex process of commercialization. Consequently, extant research offers limited theoretical conceptualization or managerial guidance on the dynamic evolving process by which firms commercialize innovative products. On this basis, our second research question is: What constitutes the commercialization process for RIs? By structuring the key process constituents and characteristics of the RI commercialization process and capturing the dynamic processual nature of commercialization, this study creates contribution to understanding the essence of commercialization.

To achieve our research goals, we chose the theory development approach and through abductive analysis, we piece together the existing theoretical knowledge fragments from the fields of innovation marketing, innovation process, and new product development, and offer empirical insights from six longitudinal cases. Longitudinal analysis is needed to capture the evolution of the 
commercialization process, but it has been seldom employed with regard to commercialization (e.g., Chiesa \& Frattini's 2011 historical analysis, O'Connor, et al.'s publications from 1998 to 2013). Most frequently, studies relating to commercialization have employed only snapshots of a single point in time to capture commercialization success (e.g., Easingwood, Moxey, \& Capleton 2006). Thus, through the longitudinal approach, we develop a dynamic process model that captures the challenges and the evolution of the commercialization process for RIs, which is our major intended contribution.

The paper is structured as follows: first, we discuss the existing knowledge on challenges, activities, and characteristics along the commercialization process, and then present our research methods. This is followed by case analyses and an examination of the results produced. Finally, we outline the theoretical contribution, as well as the limitations, and offer insights on the management of challenges and the probing approach to the commercialization process.

\section{COMMERCIALIZATION PROCESS IN RADICAL INNOVATIONS}

\subsection{Challenges complicating the commercialization process}

Since novelty seems to provoke commercialization challenges, we first discuss the facets of innovativeness. Technological discontinuity arises from operating in new technological domains and involves new processes or technologies, which might affect commercialization by complicating the design and implementation of products that fit neatly into customers' current consumption patterns (McNally, et al. 2010). Customer discontinuity refers to required changes in customers' behavior patterns that first increases their perceptions on risk and, second, requires significant learning by customers (McNally, et al. 2010). Discontinuities perceived by customers often result in barriers of not knowing and not wanting (Lettl 2007, O'Connor 1998) and difficulties in understanding the benefits, which all together create adoption barriers (Rogers 1983, Veryzer 1998). According to McNally, et al. (2010), marketing discontinuity refers to situations in which 
"firms operate in new marketing domains" with regard to changes in product category, competitors, distribution channels, or customer base. Such a shift requires learning about the new market and acquiring new resources (Costa, et al. 2004, Lynn, et al. 1996, O’Connor, et al. 2008), building a market vision on how to link an innovation's technical features to market opportunities (O'Connor \& Veryzer 2001, Reid \& de Brentani 2012), and creating new markets (O’Connor \& Rice 2013b, Sandberg 2008). However, the shift also necessitates a change in mindset towards marketing orientation and customer orientation that tends to be difficult, particularly in engineering-based firms (see Jaakkola, et al. 2010, Wiersema 2013).

Challenges are intensified if the ecosystem and divergent stakeholders (i.e., distributors, experts, regulators, and complementors) do not easily adopt the novelty (Aarikka-Stenroos \& Sandberg 2012, Chiesa \& Frattini 2011, Talke \& Hultink 2010) as they drive customer acceptance or rejection (Aarikka-Stenroos, Sandberg, \& Lehtimäki 2014, Woodside 1996). Nonetheless, particularly small firms face difficulties in networking with stakeholders (Aarikka-Stenroos \& Sandberg 2012) and developing alliances (Costa, et al. 2004). Moreover, the market's conservative nature and, for example, trust sensitiveness of the focal industry (see Sorescu, Chandy, \& Prabhu 2003) may also trigger additional challenges.

\subsection{Constituents and characteristics of the commercialization process for RIs}

We propose that the commercialization process entails a multitude of linked strategic and tactic marketing activities and decisions, which we consider process constituents. We assume that they can be overlapping, repeated, and accomplished in a variety of orders (see teleological process theory by Van de Ven 1992). Activities can originate endogenously or exogenously, such as from regulations (see Chiesa \& Frattini 2011, O’Connor \& Rice 2013b). To succeed in commercialization, a firm needs to understand the driving forces that impact innovation success in the specific context (see also Chiesa \& Frattini 2011, Easingwood, et al. 2006), and employ that 
understanding when choosing their activities and decisions.

We posit that elementary commercialization considerations amalgamate market visioning that includes initial decisions, such as which concepts to pursue (see O'Connor \& Rice 2013b, Reid \& de Brentani 2012) and who could be potential users. The vision can also imply novel business models (e.g., Markides 2006) and requires unlearning existing conventions of conducting business and developing totally new value combinations within the industry (Aarikka-Stenroos \& Sandberg 2012, Möller \& Svahn 2009).

After these decisions, initial commercial considerations move toward defining a marketing strategy, including targeting, segmentation, and positioning decisions and the identification of competitors (Chiesa \& Frattini 2011, Costa, et al. 2004).

These decisions are then implemented through tactical decisions; for example, on pricing, developing the "whole product" configuration, and establishing the distribution channels (Chiesa \& Frattini 2011, Hultink, et al. 1997). Moreover, firms need to communicate the innovation's benefits in a context relevant to customers (Athaide, Meyers, \& Wileman 1996, Lehtimäki, Simula, \& Salo 2009), and build awareness for products, educate customers, and organize trials and demonstrations (Aarikka-Stenroos \& Sandberg 2012, Sorescu, et al. 2003).

Within commercialization, the firm's ultimate aim is to initiate and develop sales according to the chosen marketing strategy. Elaborating on Moore's (2002) ideas, the early market for RIs consists of technology enthusiasts and visionaries who are open to new solutions. Such first customers enable sellers to collect feedback and information on product performance, usage, and pricing (Athaide, et al. 1996, Lynn, et al. 1996). These first sales and potential customer references facilitate later demonstrations of benefits and denote credibility to create further sales (Golder, et al. 2009, Ruokolainen \& Igel 2004).

When the commercialization moves towards the more conservative early majority, a firm needs to show that its novelty attracts a broad user base and provide evidence that the future of the 
innovation is secure (see Costa, et al. 2004, Moore 2002). To mobilize extensive dissemination, a firm needs to scale up production and distribution networks, integrate the RI into the mainstream business and production setting (Story, et al. 2011), and inspire the whole value chain and complementary and supportive market actors (Aarikka-Stenroos \& Sandberg 2012, AarikkaStenroos, et al. 2014, O’Connor \& Rice 2013b).

Furthermore, a commercialization-related marketing strategy and its implementation can be elaborated upon based on interaction with the market and identified marketing and management mistakes (see Costa, et al. 2004). This puts forward essential characteristics, such as experimentation (O’Connor 1998) and learning (Coviello \& Joseph 2012), which describe the process of commercialization when a firm aims to find the winning combination of product and market. This does not need to happen through blind trial and error as firms can be purposive in the activity (Lynn, et al. 1996, O’Connor, et al. 2008, Reid \& de Brentani 2012); however, initial "good" solutions can later generate unintended problems (Garud, et al. 2011) resulting in regressions and loops in the commercialization process.

\subsection{Synthesis: Commercialization process shaped by challenges}

Based on literature reviewed above, we propose a framework for the process of commercialization with the aim of successfully disseminating RIs to the market. Our framework includes process constituents, such as a definition of marketing strategy and marketing implementation that comprises more specific commercialization activities and decisions executed actively or reactively due to challenges faced (see Figure 1). We assume that the commercialization challenges push the firm to consider and reconsider the required commercialization activities and decisions. Together, this results in marketing strategy and marketing implementation evolution and introduces dynamic characteristics to the whole commercialization process. With this analytical framework, we will empirically investigate firms' commercialization challenges and processes for RIs. 
Place Figure 1 Here

We acknowledge that a firm's features, such as size, can shape the commercialization process. Firms with good financial resources are in a better position to bear the costs and acquire more resources required to succeed with an RI (Sorescu, et al. 2003), while smaller innovator firms often lack the necessary resources (Partanen, et al. 2011). We also posit that an innovation's features (e.g., systemic or autonomous; see Teece 1996), and a market's features, such as industry conservatism or eagerness to support new business (Möller \& Svahn 2009, Partanen, et al. 2011, Sorescu, et al. 2003), facilitate or complicate the commercialization process.

\section{METHODOLOGY}

\subsection{Research approach, design, and data gathering}

This research aims towards theory development through abductive reasoning in which theoretical conceptualizations are modified based on empirical findings, but also due to new theoretical insights gained along the process (see Andersen \& Kragh 2010, Dubois \& Gadde 2002). The case study approach was chosen due to the nature of the research questions (i.e., the focus on the longitudinal evolution of the process) and in order to examine the phenomenon in its natural setting. By selecting a multiple case strategy, we were able to both analyze in detail distinctive commercialization processes shaped by challenges, and synthesize similar patterns identified across the cases. The case unit is a commercialization process enacted by an innovator firm.

The case selection was purposive: we emphasized theoretical sampling (Flick 2002) and applied the following criteria:

- Variety of products or services from consumer and business markets, which made it 
possible to identify the generic challenges and process constituents. This was also assumed to improve the transferability of results.

- Distinctive commercialization processes. Cases were selected when preliminary interviews and newspaper articles indicated that the innovator firms faced different challenges and, consequently, were likely to have distinctive commercialization paths. The cases also range from those that are successful to several that were still embattled at the time of reporting.

- Open-minded access to firm's long and agonizing processes. This was considered to improve the quality of the data and findings. The more openly firms share their failures and incorrect decisions along the commercialization process, the better the process and challenges can be understood.

As a result, six commercialization processes by Finnish firms were selected for examination (see Table 1). Finland generally offers an appropriate context for examining innovations as it is, by several measures, among the top innovative countries in the EU (Innovation Union Scoreboard 2011). Small firms (<50 employees) were chosen in particular since RI research has focused more on large, established firms (e.g., O'Connor, et al. 1998-2001), but challenges were expected to be accentuated in smaller firms.

Place Table 1 Here

The study is longitudinal and relies on both retrospective and real-time multisource data. The primary dataset comprises in-depth interviews with representatives of the focal organizations and other key actors, such as CEOs, marketing managers, technical directors, and external experts who were directly involved in commercialization. We interviewed several respondents for each case. Most of the interviews were conducted face-to-face at the firms' head offices. Telephone 
discussions and e-mail correspondence complemented the interviews and consolidated close realtime follow-ups of the commercialization processes. In all cases, interview data were substantiated by the secondary dataset of archival-internal and media-originated data, such as technical documents, annual reports, the firms' marketing materials, books chronicling the firms' histories, research articles, newspaper articles, and web pages concerning the products, the companies, and their focal markets. Datasets exposed the innovativeness of the new product/service; the whole innovation process; the actors, activities, and decisions in the commercialization process; and the emerged challenges, successes, and failures.

\subsection{Analysis}

The analysis focused on retracing and structuring the commercialization process and identifying challenges that shaped the process. We began with the loose simplified framework outlined in figure 1. New theoretical aspects were picked up along the research process as they enhanced analysis and theorization; thus, both inductive and deductive analysis cycles occurred. This is typical for an abductive research procedure (Andersen \& Kragh 2010, Dubois \& Gadde 2002, Törnroos \& Järvensivu 2010). For example, challenges were first captured through a more datadriven procedure; however, after identifying and examining the literature on the dimensions of innovativeness, we used this literature to refine our preliminary results and elaborate on the roots of the challenges.

First, we applied within-case analysis to create an overview on each case: we identified and ordered events and constructed commercialization as a flow of linked activities, decisions, and challenges faced. To help us understand the evolution of the process, the principles of the critical event technique were applied here (see e.g., Flanagan 1954), as this facilitates examining divergent business processes (Roos 2002). This analytical phase revealed, for example, the copiousness of process pull-backs. The next step was a cross-case analysis: we compared the challenges and 
process twists in the cases and sought general patterns, and arranged the identified process patterns and challenges into zones. Thus, through several analysis rounds, the initial framework was elaborated into a dynamic process model - figure 4.

NVivo software was employed particularly for analysis of interviews as it facilitated capturing and coding analyzed items (activities, decisions, events, challenges, and specific features of the commercialization processes), and retrieving and developing solid categories for further analysis; thus, it supported systematic but flexible analytical processes (see Bazeley 2007). Moreover, we drew process pictures and organized aspects of the framework into multiple tables to construct cases, and then compared them. As multiple data sources, theoretical schemes from various research streams and multiple researchers were involved, triangulation (see Flick 2004) assumingly improves the trustworthiness of the results which are presented next.

\section{FINDINGS ON HOW FIRMS' COMMERCIALIZATION CHALLENGES EMERGE AND PROCESSES EVOLVE}

\subsection{Cases}

The six studied commercialization processes are displayed in Table 2 through case synopses. These storylines show the employed marketing strategy and its implementation, the emerged challenges, and their consequences along the commercialization process, and successes and failures in sales.

Place Table 2 Here

Next, the knowledge extracted from the cases via cross-case analysis is discussed; first, the major challenges complicating the commercialization process of RI, and then the identified process 
constituents and characteristics.

\subsection{Commercialization challenges}

The commercialization processes were complicated by technological, customer, and marketing discontinuities triggering challenges. Our analysis showed that technological discontinuity per se was not the obstacle complicating commercialization; instead, customer and marketing discontinuities often originated from technological discontinuity (e.g., in the cases of FirmBen, FirmLG, and FirmSF). Customer discontinuities meant newness of the customer's needs and of customer behavior (e.g., taking care of health proactively instead of reactive medication). Marketing discontinuities appeared as firms faced new product categories or needed to create new markets and provoke new ecosystems to make the innovations available and valuable for the customers, as well as needing to develop new ways to market their innovations. These discontinuities resulted in a number of commercialization challenges in all cases.

Through structural analysis of all commercialization processes, we identified six generic challenges, as depicted in Figure 2.

Place Figure 2 Here

Challenges were linked to each other in a fuzzy but traceable way. The dotted lines in Figure 2 illustrate the scheme and groupings of the challenges. Although the order in which the firms faced challenges varied, prime challenges required clarification before being able to overcome the 'next' challenge. For example, the challenge relating to strategic choices sets the background for subsequent activities and decisions, and accordingly, for the other challenges; and understanding the customers' perspective is needed before the firm can build credibility that matters to customers and stakeholders. However, challenges of creating credibility, acquiring support from stakeholders, 
and overcoming adoption barriers can be partly addressed in parallel. Ultimately, the challenge of creating sales is successfully tackled only after the other challenges have been addressed. The identified challenges and their links to the evolution of the commercialization process are elaborated next.

\section{1) Choosing a feasible strategy in conditions of uncertainty}

Almost all of the examined firms faced this challenge that led them to refine their original strategies after initial probing with sales, which resulted in changes to the innovation concept, targeted segments, positioning, value propositions, and the business model. Due to customer and marketing discontinuities, the firms had no full information or experience of the market's responses and had only a preliminary understanding of a potential market with a special need; thus, under conditions of high uncertainty, developed the initial strategies with high goals (e.g., fast entry and large markets). In several cases, the firms garnered positive initial responses from potential partners and customers, and interpreted these as intentions to buy or enter into partnerships, which raised the firms' expectations further. However, it was soon realized that the strategic goals were exaggerated for firms with minor resources or insufficient network relations and ecosystems. The goals proved to be impossible to achieve as market creation and preparation were neglected. Changes of strategy were experienced in all of the cases, causing dissonance and often changes of CEOs (i.e., organizational uncertainty in O'Connor \& Rice 2013a). When a firm's original strategy encountered setbacks due to an unexpected market response or a lack of existing markets or ecosystems, the firm needed to consider whether to refine its strategy or adopt a stance of greater resilience.

"We are now at some kind of crossroads: what kind of business will we target? Is it BtoC or something else? Thus far, we have done both, but probably we will be aiming at consumer markets with the new product after all. Let's see. Our shareholders have really different opinions on the way we should go. " CEO, FirmNT

FirmNT envisioned huge potential for its monitor and, despite scarce resources, it chose to target 
global consumer markets, instead of, for example, more specialized expert niche markets. It tried to achieve this goal by inducing resource-increasing cooperation with wellness-related partners, but still failed to create a functional ecosystem around the innovation and to achieve success with international buyer candidates, until finally, its resources were exhausted. FirmBen first chose the "wrong" market area based on "wrong" assumptions with a "wrong" partnering policy as it targeted the large US market. This proved too challenging for its health product that required favorable legislation on the consumer benefit, and the building of partner and consumer awareness concerning the lowering of cholesterol. In brief, they needed to revise their initial strategy as they ran into marketing discontinuities, since their innovation created a new product category as well customer discontinuity, and the customers did not yet understand or appreciate the benefits of the innovation. The company rapidly developed a totally new partnering strategy after analyzing what went wrong, and achieved success. FirmUni soon learned that its chosen strategy would not realize market breakthrough in the chosen territory; it identified a variety of other potential markets and decided to probe simultaneously several alternative strategies. Hence, the implementation of the original strategy revealed requirements for strategic and tactical remodifications in almost all cases.

Early interaction with stakeholders - not only users but also distributors, complementors, and legislators -facilitated development of the market knowledge and a feasible marketing strategy. FirmEx was the only case company that involved R\&D actors and novel commercialization stakeholders to create demand pull for the product that then facilitated sustaining its original strategy and achieving the target market. The other firms examined were either unable or reluctant to engage in such interaction sufficiently early as they feared their ideas would be stolen, or believed that sales would simply take off.

\section{2) Understanding the customer's perspective}

The firms perceived challenges in communicating and demonstrating the benefits of its 
innovation. However, for all studied firms, the real challenge was that they did not yet understand the benefits from the customers' perspective (i.e., customer value). Hence, the experienced marketing discontinuity was rooted in the underlying customer discontinuity: the RIs created new product categories which then needed to be matched and attached to latent customer needs. However, understanding those needs required significant effort from the firms as it necessitated interaction, openness, and the readiness to adapt one's insight, which seemed to be intractable for some firms:

"In the beginning our sales were - how to say - very technologically based. We emphasized the technical aspects, molecules and so on, and also sales persons were engineers, biologists, and chemists, and then, step-by-step, we started to see this business from the viewpoint of customers and how we should approach them." CEO, FirmBen

The quotation reveals a common mindset and focus among the case companies: the firms focused on technological discontinuity and managing it, even though, early on, they should also focus on subsequent customer and marketing discontinuities, that is, how technological novelty benefits the customer and what kind of marketing is, therefore, required. The case firms were often fascinated by the technical benefits they perceived in their respective innovations and built their initial sales efforts around them. However, after discussions with and presentations to stakeholders and particularly customers, the customers' perspective on benefits and value potential, their preferences, and the potential use contexts began to transpire. Firms then realized the need to reconsider their perceptions from the user perspective and to adjust their plans to whom the innovation might be truly valuable and why. For example, FirmLG needed to reconsider the communication of its LED innovation's benefits as the targeted customers did not value the quality of the light, which was perceived as a key benefit by the firm. FirmSF discovered that some benefits of its novel service were considered "too good to be true" and aroused suspicion in the risk-averse target markets, thereby diminishing its benefits in communications. FirmEx realized that even though its walking poles were offering benefits, they also generated high psychological costs, such as embarrassment (i.e., standing out in the crowd, see Aggarwal, Taihoon, \& Wilemon 
1998), that destroyed customer value originating from the product; this, therefore, needed to be diminished by rapidly creating a critical mass of user adopters.

Moreover, several firms learned that some benefits and the associated behavioural changes required were perceived controversially among customers. For example, in the case of FirmSF, the service generated cost savings that pleased financial managers in potential customer firms, but at the same time, reduced the number of work positions and the power of research managers who, as experts, were equally involved in valuing and buying the innovative service.

\section{3) Creating credibility for the innovation and the firm}

The challenge of credibility originates mainly from the technological innovativeness and the related marketing discontinuity, namely the newness of the product category and the potential lack of the supporting ecosystem. The proposed novel benefits of a product/service are faced with a profusion of divergent rival novel technological deliverables. In addition, a firm's small size, or the extent to which it is unknown in the focal market, fortifies this challenge. This led the innovator firms to put special effort into showing that they are credible actors with credible products or services.

"One of our strengths has been that our business is so solidly based on scientific evidence. Credibility of our business is extremely important; it's important when we acquire partners but also when partners then commercialize the product to local consumers. There must be something that really works. Our product is not a marketing trick." CEO, FirmBen

To fortify credibility, the firms developed various partnering and networking strategies, and validated the innovation and its benefits through scientific evidencing and testing, customer references and awards, educating customers, and employing established brands. For example, FirmEx had a strong brand and known partners, which can be assumed to have lessened the impact of this challenge in their commercialization process.

Transferring credibility from other markets or products to serve the commercialization of an RI seems to be difficult. For example, FirmNT had a good reputation and strong customer references 
due to its other high-tech wellness product in BtoB markets. Consequently, it managed to increase the credibility of its osteoporosis-prevention monitoring technology, supported by scientific test results, but failed to strengthen credibility of the consumer product concept per se. A probable reason for this is because the firm was a small and new player in consumer markets. FirmLG had references from other markets for its technology, but it struggled with the innovation's credibility due to a competitor's earlier unsatisfactory LED product, and technical experts' outdated knowledge about the possibilities of the current LED technology. Therefore, they aimed to increase the product credibility, first through expert lecturing and, subsequently, with first references:

"LED technique has had a reputation of a piffling technique; it dazzles but does not enlighten. It has been a real challenge for us, this kind of rapidly increasing and developing technique. With the first products we were able to show that, OK, for the first time there is a LED lamp that really works as street lighting. Then some of them also worked as reference cases with which we could state that: there they are, just go and look." Strategic and design consultant, FirmLG

\section{4) Acquiring support from relevant stakeholders and incorporating an innovation into an} ecosystem

To develop a supportive operational surrounding for their RIs, firms need to enter and modify existing ecosystems, or create an entirely new ecosystem (cf., Möller \& Svahn 2009). Thus, the challenge triggered by this marketing discontinuity was how to acquire support from stakeholders. The cases show that firms needed both to identify critical stakeholders and then to involve and mobilize them through formal and informative relations and partnerships. This challenge was particularly crucial for systemic innovations since they require support from stakeholders and a functioning ecosystem for providing value (e.g., the food ingredient by FirmBen).

Involvement of diverse stakeholders is also relevant because, based on all of the cases, they can support commercialization in many ways, such as by coping with legislation and standards, understanding the dynamics and conventions of the market, developing broader solutions, supporting the emergence of complementary offerings, or organizing novel distribution channels. They can educate and demonstrate benefits, and help form a critical mass behind the innovation. 
For example, FirmEx employed experts and lead users that supported credibility and user education, and eventually succeeded in also involving distributors which first refused to participate. FirmNT tried to create a similar supporting network, although it failed to involve, activate, and mobilize the parties. FirmBen put effort in attracting the experts:

"We need to sell the idea of our product also to healthcare professionals, because if a doctor says that our product is humbug, it is clear that consumers will not use it. Therefore, we have special representatives who circulate and meet doctors, health nurses, and other healthcare experts, and present facts and results of clinical tests and scientific evidence on our products." CEO, FirmBen

In particular, distributors are critical stakeholders in respect of consumer products, as they make the innovation available to end users, while often being conservative and risk-averse by nature. Another critical stakeholder group seemed to be regulators because innovator firms often face undeveloped standards and legislation for novel product categories, which can both hamper and complicate new business; however, new standards may also create new opportunities (see FirmBen and FirmLG, Table 2).

\section{5) Overcoming adoption barriers and facilitating adoption}

In all cases, the RIs represented new product categories and required changes in attitude, behavior, or processes (e.g., switching to LED technology for street lighting), or completely new behavior by customers and other relevant stakeholders (e.g., putting effort into proactive health care). Hence, this challenge rests on customer and marketing discontinuities. To overcome the emerged adoption barriers (such as risk aversion), the first step for the firms was to identify them:

"The street lighting business is really complicated because decisions are mostly taken by public servants and politicians who are, for the most part, afraid that they will make a mistake. That is why their ability to buy new innovative products is really low, and they prefer the old ones." Strategic and design consultant, FirmLG

"The whole pharmaceutical business is conservative and risk-averse. Decision makers think that they earn their bonuses anyway. If they choose to be visionary and pioneering and save time with our solutions, it is a risk that in a bad situation means that they will lose their jobs, merits, houses, cars, their feeling of safety." CEO, FirmSF 
Then, to overcome adoption barriers of not knowing and not wanting (Lettl 2007), the firms were pushed to create and prepare markets through, for example, awareness building, education, instruction, and encouraging customers to break free from old conventions. It is notable that customer education not only concerned the use or benefits of an innovation, but also promoted phenomena to which the innovation was related (e.g., LED conversion bringing savings; proactive cholesterol lowering; importance of bone exercise). However, this is often resource consuming and only tentatively supports commercialization of the focal product per se.

The results show that all adopters (e.g., users, distributors, complementors, and legislators) needed to be prepared. For example, FirmEx eventually achieved success after a poor start with reluctant distributors when it began to collaborate with lead users, partners, and experts who, through education, instruction, and encouragement, created awareness and market pull for its new product, and thus helped to overcome the adoption barriers of both distributors and end users.

\section{6) Creating sales particularly in the early majority market}

This pivotal challenge of sales generation was apparent in all cases: sales did not take off as expected if the preliminary challenges were not yet solved, which forced the firms to return to either strategy development or market creation and preparation.

"Of course we knew that the sales will be the most difficult part, but we had no idea that it would be this difficult: it does not depend on that our sales representatives would not try or be good enough or that we managers are not doing enough legwork. Instead, it somehow depends on that we should do more marketing or do something directly with the potential end-users or do something out-of-the-box." CEO, FirmUni

Particularly, customer and marketing discontinuities triggered specific difficulties relating to initial sales creation and later sales development. First, there was a typical paradoxical dilemma whereby small firms need investors and distribution partners to build sales, but these same actors first require evidence of initial sales and market potential.

Second, several of the case companies succeeded in gaining initial sales and references from the 
early market, but still struggled to accelerate and develop sales in the early majority market. These notions prove that a different approach is needed to capture the sales potential of the majority as opposed to that of early adopters (cf., 'getting over the chasm' by Moore 2002). For example, FirmNT created initial sales easily among heavy users of health products through its web shop, but then failed to increase sales among its ultimate target market, "average females globally."

In sum, most of the firms faced serious problems as they could not reach their major markets, which pushed them to reconsider their strategy or market preparation tactics.

\subsection{Constituents and characteristics of the commercialization processes}

The case analyses also reveal key constituents of the commercialization process. Relying on the linked identified challenges and commercialization activities and decisions of the firms (see Figure 3), we discovered that the commercialization processes comprised three major zones:

1) defining marketing strategy, including developing knowledge on the market, customers, and ecosystems; identification of stakeholders, and potential attractive benefits of the innovation for the market;

2) creating and preparing the market, including building awareness; educating the market; demonstrating and communicating benefits; credibility building for the firm and product/service; involving and activating stakeholders; and

3) creating and developing sales, including acquiring initial sales and customer references; mobilizing stakeholders, and increasing sales.

Furthermore, process characteristics became visible when analyzing how identified challenges, and both predetermined and reactive commercialization activities and decisions, shaped commercialization in all cases (see Figure 3). First, instead of a straightforward process, the commercialization process for RI evolves through moves back and forth between the three zones. The zones represent commercialization activity areas requiring divergent efforts from a firm; they 
are not stages or phases as firms can work on them on several occasions during the commercialization process. A zigzagging pattern through the zones, making the process nonlinear, was apparent in all cases: the firms began to follow their initial commercialization strategy and execute chosen activities, but then faced challenges requiring them to reconsider their activities, and even the original strategy. How successfully the firm was able to overcome challenges through reconsiderations shaped the whole process and the amount of zigzagging between the zones. If successful, they were eventually able to move to sustaining commercialization (i.e., out of the zones in Figure 3).

Place Figure 3 Here

Second, due to the newness of RIs, customer and other stakeholder responses are capricious and changing, making the commercialization process unpredictable. Even though the case firms employed earlier commercialization experiences and also marketing experts, this did not ensure success as, with RIs, no one can be certain how an innovation should be commercialized.

Third, the commercialization process involves continuous experimenting and iterative probing: firms need to explore workable commercialization activities and implement both planned and reactive commercialization activities as a response to stakeholders' unexpected feedback, as well as seek activities that are the key to further success. This generates learning that helps refine commercialization decisions and activities, as it is impossible to know beforehand what is certain to work.

Fourth, the process is interactive as feedback from customers, distributors, legislators, experts, and complementors develops a firm's understanding of the benefits and antecedents for adoption from the customers' and stakeholders' perspective. Such interaction generated various contributions for commercialization in the cases as it enhanced both the strategies of the firms and their 
implementation (e.g., polishing communication about customer-value generating benefits, and employing users and stakeholders for customer education).

\subsection{Dynamic model for the commercialization process of RIs: three zones}

Based on our results, we propose a dynamic model for the commercialization process that captures the challenges, the process constituents (zones and the related activities) to respond to those challenges, and the complex, evolving and interactive probing characteristics of the commercialization process for RIs (Figure 4).

Place Figure 4 Here

Technological innovativeness triggers customer and marketing discontinuities, which in turn may have mutual implications for each other. For example, newness of the customers' need might require creating a new ecosystem around the innovation, and a new product category might ask for a new kind of behavior from customers. These discontinuities trigger identified challenges along the commercialization process and introduce dynamics concerning what particular commercialization activities are essential.

The model comprises three linked zones: strategic zone, market creation and preparation zone, and sales creation and development zone. Marketing strategy is the fundamental core of the strategic zone and of the whole commercialization process. It influences and guides marketing implementation for commercialization while, simultaneously, strategy is often refined through interactions with markets as a firm accumulates knowledge of a market, identifies (and possibly already involves) potential customers, and realizes the perspectives of multiple customers and stakeholders on an innovation's benefits.

The middle zone, market creation and preparation, appeared to be vital as its activities aim to facilitate adoption by changing customers' mindsets favorably towards the innovation. Yet, in the 
studied cases, this zone was often neglected as the firms (and investors) were keen to move quickly to sales creation; however, the firms then faced serious difficulties in creating and developing sales. The findings clearly indicate that the more innovative the product or service from the market's perspective, the longer and more cumbersome the path in the market preparation zone. If the market did not exist at all (e.g., the need was new), a firm needed to really dedicate effort to this zone by educating customers, and creating an active supportive network of divergent stakeholders. Since adoption is influenced by multiple stakeholders (i.e., from regulators and distributors to experts and

end users), preparation activities should be directed at all of these actors. This zone was particularly problematic for small firms, as it easily consumed time and resources.

Within the outermost zone, sales creation and development, a firm begins to generate and gradually increase sales and growth through striking initial deals, acquiring reference customers, and mobilizing stakeholders to contribute to commercialization, such as other firms providing complementary offerings or delivering the product. Based on our analysis, firms are able to grow sales only if they have managed the earlier zones well.

\section{CONCLUSIONS AND IMPLICATIONS}

\subsection{Major results and theoretical contribution}

As so much research has focused on research and development and fuzzy front-end epochs of the RI process, this study focused on the commercialization of RIs occurring as a process shaped by challenges originating from innovativeness. The key result, the dynamic commercialization process model for RIs, brings three major contributions.

First, we identify six challenges that complicate the commercialization process of RIs: choosing a feasible strategy, understanding the customer's perspective, creating credibility, acquiring support from the ecosystem, overcoming adoption barriers, and creating sales. By classifying major commercialization challenges, and binding them to the commercialization process, we contribute to 
the literature that has suggested some challenges affecting commercialization and marketing of RIs (e.g., Chiesa \& Frattini 2011, Costa, et al. 2004, O’Connor \& Rice 2013a, 2013b).

Second, as the process perspective and longitudinal research designs are missing from the current research on commercialization, through multiple longitudinal case analyses we captured and conceptualized the composition of the commercialization process for RIs. We identified the three zones (strategic, market creation and preparation, and sales creation and development) as the key process constituents through which the dynamic commercialization process evolves for RIs, and the characteristics of such a process. Thus, we develop insights on commercializing RIs in particular (e.g., O’Connor \& Rice 2013b, Story, et al. 2009, Story, et al. 2011), and on marketing innovations (Costa, et al. 2004, O’Cass \& Ngo 2011). Our results emphasize that all three critical zones of the commercialization process need to be sufficiently addressed to achieve successful sales.

Particularly, neglecting the market preparation and creation zone seems to be a major reason for RI commercialization failures: the extreme novelty requires intensive work on market preparation and creation activities before initial sales. Nonetheless, our study shows that firms tend to rush from early strategic decisions to sales creation with a relatively shallow understanding of the market or the fit with customer needs and the ecosystem, and consequently, they fail. In brief, it is often surprisingly difficult to leverage initial interest into sales as it requires careful market preparation.

Third, due to our longitudinal approach to commercialization, our research captured the dynamic nature of the process that originates from its identified characteristics (zigzagging pattern unpredictability, iterative probing, and interactive nature). The longitudinal approach also enabled us to capture partial failures and successes along the processes, thereby deepening the current knowledge on commercialization that often roughly perceives commercialization as being either successful or non-successful (Chiesa \& Frattini 2011, Costa, et al. 2004, Easingwood, et al. 2006). The progression of the process and the relevant commercialization activities are not foreseeable by or evident to even experienced managers and experts; emphasizing the reactive aspects of the 
process. No firm is immune to having to probe and face unexpected challenges along the commercialization process. Therefore, the commercial success of an RI depends on how well managers address the inherent unanticipated uncertainties relating to RIs (see O'Connor \& Rice 2013a). Early interaction with relevant stakeholders seems to be crucial as they provide feedback and trigger learning about the benefits, adoption barriers, and sales, and thus enable a firm to focus on optimal commercialization activities. Previous research has noted that customers advance the development of an RI (e.g., Coviello \& Joseph 2012, Lettl 2007), but our study extended this knowledge by showing how customers and other stakeholders specifically contribute to commercialization. This is an important aspect as firms tend to neglect the ability of multiple stakeholders beyond the customer to contribute to innovation throughout the process (AarikkaStenroos \& Sandberg 2012, Coviello \& Joseph 2012, Partanen, et al. 2011).

\subsection{Managerial implications}

Based on our findings, we offer several management proposals. First, managers are tempted to overestimate the attractiveness of a novelty and its proposed benefits, and their capability to take it to the market, but they should not rush into sales without early interactive probing or they might end up exhausting their resources. Instead, they should pay attention to market preparation and creation that requires resources and careful work. Key partners and stakeholders should be identified and engaged in interaction to develop market understanding for commercialization, to increase credibility and feasibility, and to develop the required ecosystem around the RI. This may save firms from some failures and reduce some zigzagging, at least the premature jump to putting efforts into sales creation.

Second, to manage the twists and turns and accumulating challenges of the commercialization process of RIs, managers need to understand how the challenges are linked, and in which order they can eventually be overcome. Managers can employ the proposed model to analyze their own 
commercialization processes, and be more aware of the most critical activities and challenges ahead.

Third, managers should be aware that challenges, probing, and fluctuating between successes and failures is a natural "must" that is required to find the winning combination of concept, business model, and target markets, and to delineate the optimal commercialization decisions and activities required to succeed. Figure 4 compiles the whole commercialization process including common challenges, and urges managers to realize how much effort is required for successful commercialization even after a product/service is "ready."

\subsection{Limitations and emerged issues for further research}

Our findings stem from the commercialization paths of a set of purposely chosen firms. The varied set of cases reveals the common ground for the commercialization process and challenges of RIs across diverse industries. Our conceptualizations concerned both BtoB and BtoC firms and firms offering products and services, but studies on other firms or specific industries might yield different answers. Also, as many of the examined firms were SMEs, a paucity of resources and the need for supporting stakeholders might be accentuated. Nevertheless, our findings are likely to be more widely applicable, as even large firms are seldom able to create markets and ecosystems alone, and face similar customer and marketing discontinuities in developing RIs. Therefore, we call for a longitudinal examination on mature larger firms with a wide range of diverse products, intangible and tangible resources such as strong brands, capital, and knowledge, and ask: how do they address different commercialization processes for RIs?

Commercialization has been identified as one of the RI competencies (Story, et al. 2009, Story, et al. 2011), and based on our findings, we suggest that this needs further examination as it appears to comprise several important competencies relating to strategic decision making, market preparation, and sales creation, which often develop along the commercialization process. As 
market preparation seems to be crucial for innovation success, we urge researchers to focus more on this aspect.

Finally, we see that front end, R\&D, and commercialization activities overlap and interact, and decisions made in one often impact other activities; this requires more longitudinal research designs that follow such interplay along the innovation process. 


\section{References}

Aarikka-Stenroos, L., Sandberg, B., \& Lehtimäki, T. (2014, Forthcoming). Networks for the commercialization of innovations: A review of how divergent network actors contribute. Industrial Marketing Management, 43(3), 365-381.

Aarikka-Stenroos, L., \& Sandberg, B. (2012). From new-product development to commercialization through networks. Journal of Business Research, 65(2), 198-206.

Aggarwal, P., Taihoon, C., \& Wilemon, D. (1998). Barriers to the adoption of really-new products and the role of surrogate buyers. Journal of consumer marketing, 15(4), 358-371.

Andersen, P. H. \& Kragh, H. (2010). Sense and sensibility: Two approaches for using existing theory in theory-building qualitative research. Industrial Marketing Management, 39(1), 49-55.

Athaide, G. A., Meyers, P. W., \& Wilemon, D. L. (1996). Seller-buyer interactions during the commercialisation of technological process innovations. Journal of Product Innovation Management, 13(5), 406-421.

Bazeley, P. (2007). Qualitative Analysis with NVivo. London, UK: Sage Publications.

Chiesa, V., \& Frattini, F. (2011). Commercializing technological innovation: Learning from failures in high-tech markets. Journal of Product Innovation Management, 28(4), 437-454.

Cooper, R. G. (2011). Perspective: The Innovation Dilemma: How to Innovate When the Market Is Mature. Journal of Product Innovation Management, 28(s1), 2-27.

Costa, C., Fontes, M., \& Heitor, M. V. (2004). A methodological approach to the marketing process in the biotechnology-based companies. Industrial Marketing Management, 33(5), 403-418.

Coviello, N., \& Joseph, R. M. (2012). Creating major innovations with customers: insights form small and young technology firms. Journal of Marketing. 76(6), 87-104.

Crawford, M., \& Di Benedetto, A. (2008). New products management (9th ed.). New York: McGraw-Hill.

Dubois, A., \& Gadde, L.-E. (2002). Systematic combining: an abductive approach to case research. Journal of Business Research, 55(7), 553-560.

Easingwood, C., Moxey, S., \& Capleton, H. (2006). Bringing high technology to market: Successful strategies employed in the worldwide software industry. Journal of Product Innovation Management, 23(6), 498-511.

Flanagan, J. C. (1954). The Critical Incident Technique. Psychological Bulletin, 51(4), 327-358.

Flick, U. (2002). An Introduction to Qualitative Research (2nd ed.). London: Sage.

Flick, U. (2004). Triangulation in qualitative research. In Companion to qualitative research, Uwe Flick, Ernst von Kardorff, \& Ines Steinke, eds. Pp. 178-183. London: Sage publications.

Garcia, R., \& Calantone, R. (2002). A critical look at technological innovation typology and innovativeness terminology: a literature review. Journal of Product Innovation Management, 19(2), 110-132.

Garud, R., \& Karnøe, P. (2001). Path creation as a process of mindful deviation. In Path dependence and creation, R. Garud, \& P. Karnoe, eds. Pp. 1-38. Mahwah: Lawrence Earlbaum and Associates Publishers.

Garud, R., Gehman, J., \& Kumaraswamy, A. (2011). Complexity arrangements for sustained innovation: Lessons from 3M corporation. Organization Studies, 32(6), 737-767.

Golder, P. N., Shacham, R., \& Mitra D. (2009). Innovations' origins: when, by whom, and how are radical innovations developed? Marketing Science, 28(1), 166-179.

Harrison, D., \& Waluszewski, A. (2008). The development of a user network as a way to re-launch an unwanted product. Research Policy, 37(1), 115-130.

Hitsch, G. J. (2006). An empirical model of optimal dynamic product launch and exit under demand uncertainty. Marketing Science, 25(1), 25-50.

Hultink, E. J., Griffin, A., Hart, S., \& Robben, H. S. J. (1997). Industrial new product launch strategies and product development performance. Journal of Product Innovation Management, 14(4), 243-257.

Innovation Union Scoreboard (2011). Available at: http://ec.europa.eu/enterprise/policies/innovation/files/ius-2011_en.pdf.

Jaakkola, M., Möller, K., Parviainen, P., Evanschitzky, H., \& Mulchbacher, H. (2010). Strategic marketing and business performance: A study in three European 'engineering countries'. Industrial Marketing Management, 39(8), 1300-1310.

Jolly, V. K. (1997). Commercializing new technologies. Boston: Harvard Business School Press.

Järvensivu, T. \& Törnroos J.- $\AA$. (2010) Case study research with moderate constructionism: Conceptualization and practical illustration. Industrial Marketing Management, 39(1), 100-108

Koen, P., Ajamian, G., Burkart, R., Clamen, A., Davidson, J., D'Amore, R., Elkins, C., Herald, K., Incorvia, M., Johnson, A., Karol, R., Seibert, R., Slavejkov, A., \& Wagner, K. (2001). Providing clarity and a common language fo the "fuzzy front end". Research Technology Management, 44(2), 46-55.

Lehtimäki, T., Simula, H., \& Salo, J. (2009). Applying knowledge management to project marketing in a demanding technology transfer project: Convincing the industrial customer over the knowledge gap. Industrial Marketing Management, 38(2), 228236.

Leifer, R., O'Connor, G. C., \& Rice., M. (2001). Implementing radical innovation in mature firms: The role of hubs. Academy of Management perspectives, 15(3), 102-113. 
Lettl, C. (2007). User involvement competence for radical innovation. Journal of Engineering and Technology Management, 24(1-2), $53-75$.

Lynn, G. S, Morone, J. G., \& Paulson, A. S. (1996). Marketing and discontinuous innovation: the probe and learn process. California Management Review, 38(3), 8-37.

Markham, S. K. (2013). The impact of front-end innovation activities on product performance. Journal of Product Innovation Management, 30(S1), 77-92.

Markides, C. (2006). Disruptive innovation: In need of better theory. Journal of Product Innovation Management, 23(1), 19-25.

McDermott, C. M., \& O’Connor, G. C. (2002). Managing radical innovation: an overview of emergent strategy issues. Journal of Product Innovation Management, 19(6), 424-438.

McNally, R. C., Cavusgil, E., \& Calantone, R. J. (2010). Product innovativeness dimensions and their relationships with product advantage, product financial performance, and project protocol. Journal of Product Innovation Management, 27(7), 9911006.

Moore, G. A. (2002). Crossing the chasm: Marketing and selling disruptive products to mainstream customers. New York: HarperCollins Publishers.

Möller, K., \& Svahn, S. (2009). How to influence the birth of new success fields - Network perspective. Industrial Marketing Management, 38(4), 450-458.

O’Cass, A \& Ngo, L. V. (2011). Winning through innovation and marketing: Lessons from Australia and Vietnam. Industrial Marketing Management, 40(8), 1319-1329.

O’Connor, G. C. (1998). Market learning and radical innovation: A cross case comparison of eight radical innovation projects. Journal of Product Innovation Management, 15(2), 151-166.

O'Connor, G. C., \& DeMartino, R. (2006). Organizing for radical innovation: an exploratory study of structural aspects of RI management systems in large established firms. Journal of Product Innovation Management, 23(6), 475-497.

O’Connor, G. C., \& Rice, M. P. (2013a). A comprehensive model of uncertainty associated with radical innovation. Journal of Product Innovation Management, 30(S1), 2-18.

O’Connor, G. C., \& Rice, M. P. (2013b). New market creation for breakthrough innovations: enabling and constraining mechanisms. Journal of Product Innovation Management, 30(2), 209-227.

O'Connor, G. C., \& Veryzer, R. W. (2001). The nature of market visioning for technology-based radical innovation. Journal of Product Innovation Management, 18(4), 231-246.

O’Connor, G. C., Hendricks, R., \& Rice M. P. (2002). Assessing transition readiness for radical innovation. Research Technology Management, 45(6), 50-56.

O’Connor, G. C., Ravichandran, T., \& Robeson, D. (2008). Risk management through learning: management practices for radical innovation success. Journal of High Technology Management Research, 19(1), 70-82.

Partanen, J., Chetty, S. K., \& Rajala, A. (2011). Innovation types and network relationships. Entrepreneurship Theory and Practice, May(early view), 1-29.

Prebble, D. R., de Wall, G. A., \& de Groot, C. (2008). Applying multiple perspectives to the design of a commercialisation process. $R \& D$ Management, 38(3), 311-320.

Prenkert, F. (2012). Commentary to "From new-product development to commercialization through networks". Journal of Business Research, 65(2), 207-209.

Reid, S. E., \& de Brentani, U. (2010). Market vision and market visioning competence: Impact on early performance for radically new, high-tech products. Journal of Product Innovation Management, 27(4), 500-518.

Reid, S. E., \& de Brentani, U. (2012). Market vision and the front end of NPD for radical innovation: The impact on moderating effects. Journal of Product Innovation Management, 29(S1), 124-139.

Rogers, E. M. (1983). Diffusion of innovations. New York: The Free Press.

Roos, I. (2002). Methods of investigating critical incidents. Journal of Service Research, 4(3), 193-204.

Ruokolainen, J., \& Igel, B. (2004). The factors of making the first successful customer reference to leverage the business of start-up software company - Multiple case study in Thai software industry. Technovation, 24(9), 673-681.

Sandberg, B. (2008). Managing and marketing radical innovations: Marketing new technology. Routledge Studies in innovation, organization and technology. Milton Park, Abingdon, Oxon: Routledge.

Schilling, M. A. (2005). Strategic management of technological innovation. New York: McGraw-Hill.

Song, X. M., \& Montoya-Weiss, M. M. (1998). Critical development activities for really new versus incremental products. Journal of Product Innovation Management, 15(2), 124-135.

Sorescu, A. B., Chandy, R. K., \& Prabhu, J. C. (2003). Sources and financial consequences of radical innovation: Insights from pharmaceuticals. Journal of Marketing, 67(4), 82-102.

Story, V., Hart, S., \& O’Malley, L. (2009). Relational resources and competences for radical product innovation. Journal of Marketing Management, 25(5-6), 461-481.

Story, V., Hart, S., \& O’Malley, L. (2011). Roles, role performance, and radical innovation competences. Industrial Marketing Management, 40(6), 952-966. 
Talke, K., \& Hultink, E. J. (2010). Managing diffusion barriers when launching new products. Journal of Product Innovation Management, 27(4), 537-553.

Teece, D. J. (1996). Firm organization, industrial structure, and technological innovation. Journal of Economic Behavior \& Organization, 31(2), 193-224.

Van de Ven, A. H. (1992). Suggestions for studying strategy process: a research note. Strategic Management Journal, 13(s1), 169188.

Veryzer, Jr. R.W. (1998). Key factors affecting customer evaluation of discontinuous new products. Journal of Product Innovation Management, 15(2), 136-150.

Veryzer, R. W. (2005). The roles of marketing and industrial design in discontinuous new product development. Journal of Product Innovation Management, 22(1), 22-41.

Wiersema, F. (2013). The B2B agenda: The current state of B2B marketing and a look ahead. Industrial Marketing Management, 42(4), 470-488

Woodside, A. G. (1996). Theory of rejecting superior, new technologies. Journal of Business \& Industrial Marketing, 11(3/4), $25-43$. 
Figure 1 A framework for the process of commercialization.

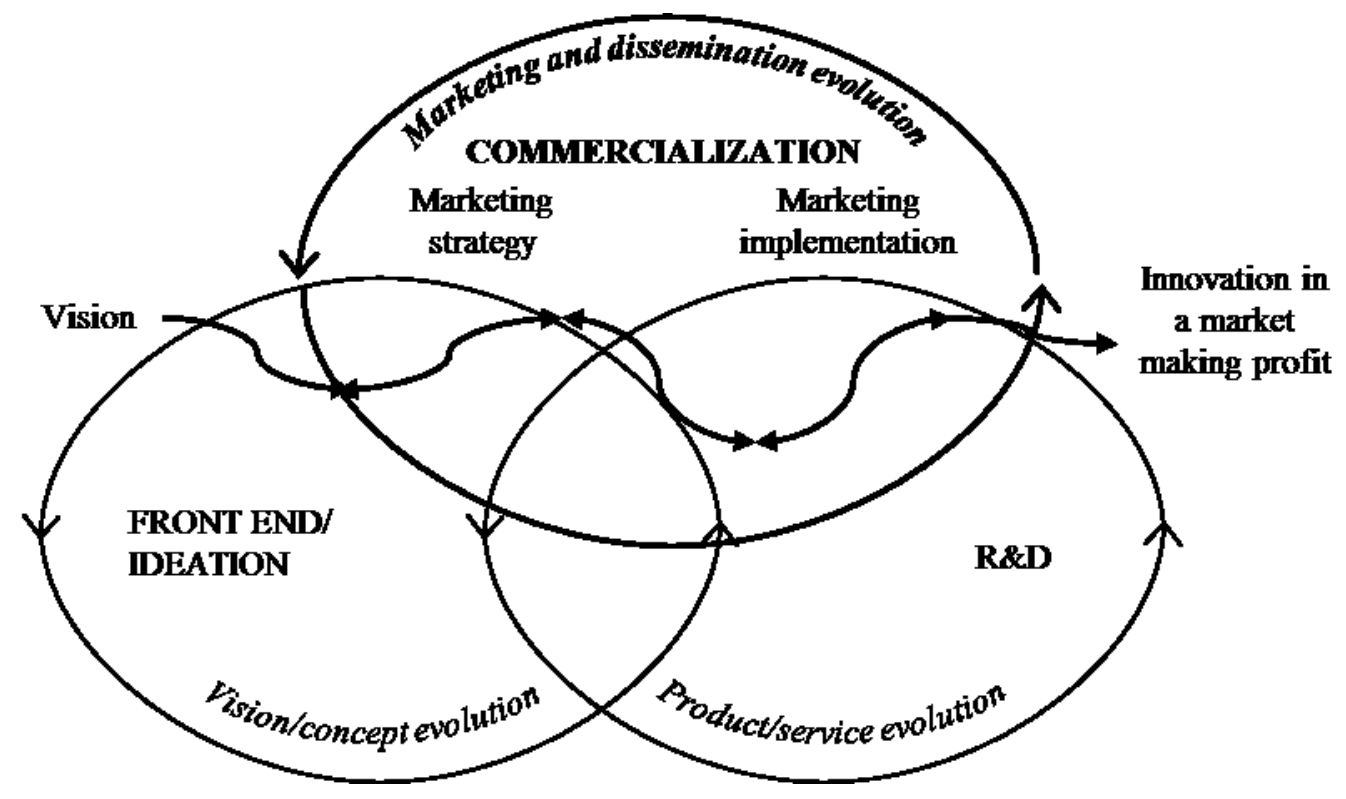


Figure 2. Identified commercialization challenges and their linkages

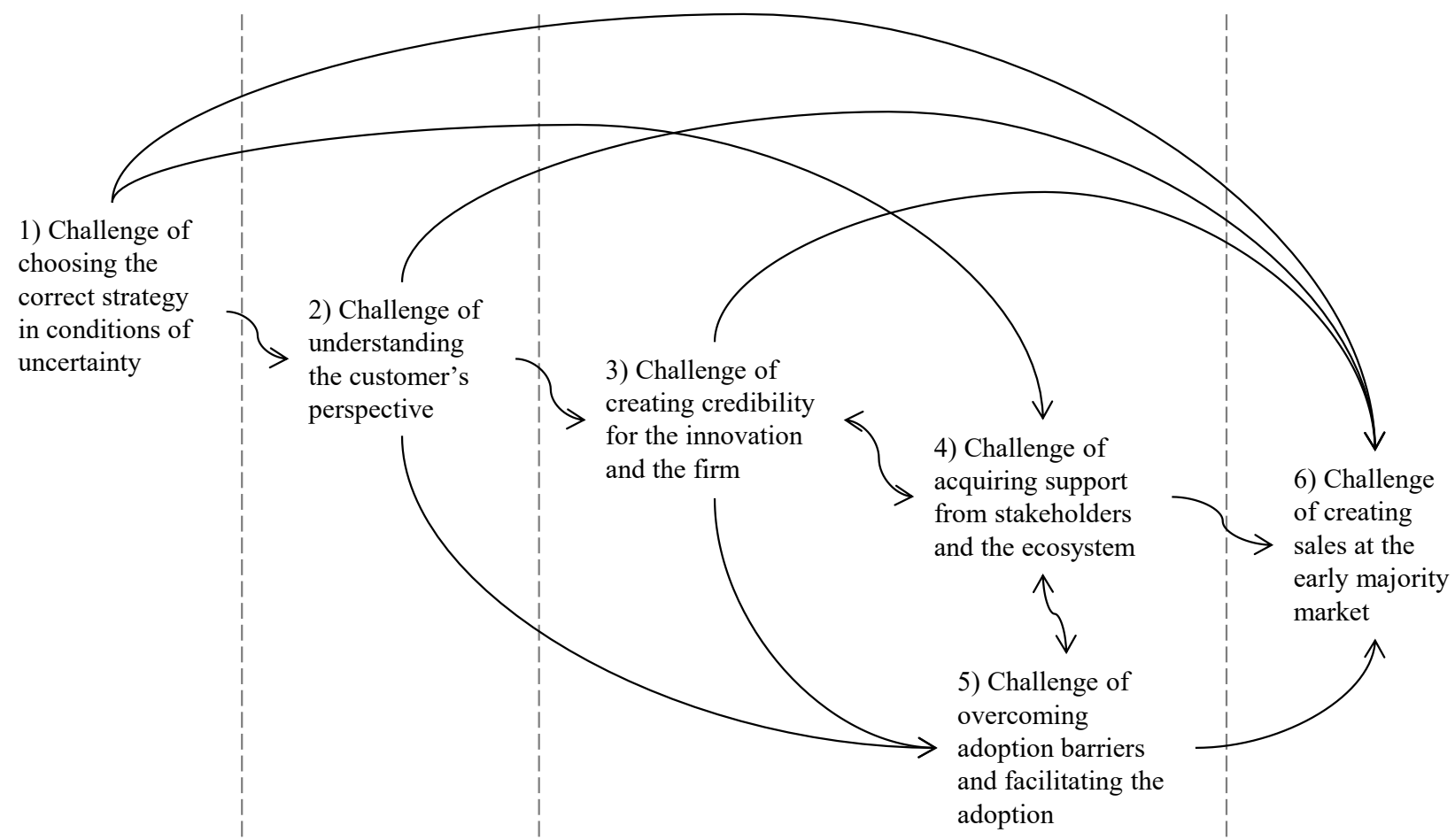


Figure 3. Illustration of commercialization processes experienced: the pattern of moving back and forth between the zones (see also Table 2)

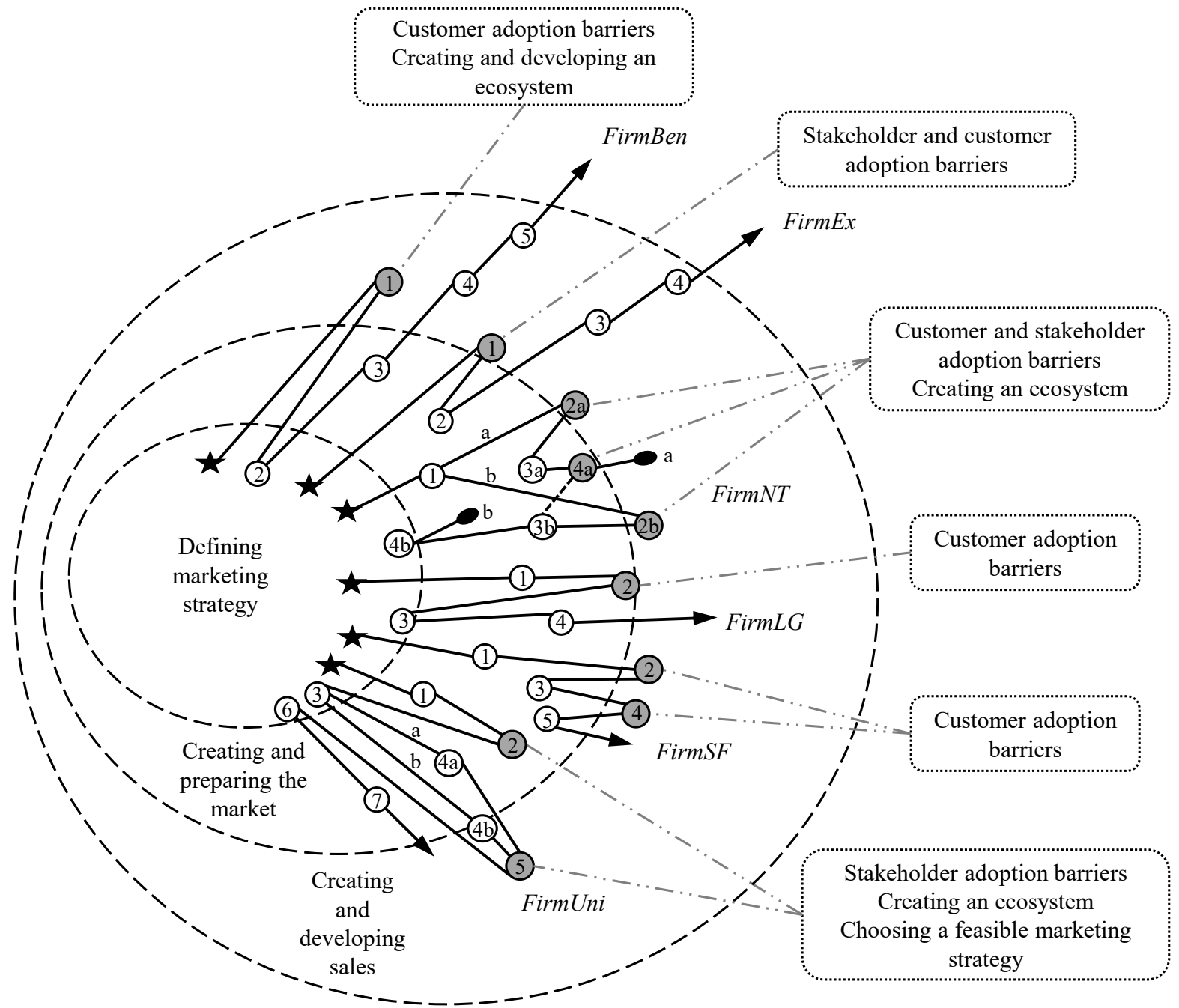

Key: $\quad \star$ Indicates the setting of the initial marketing strategy/strategies

DOT indicates activities to overcome a challenge

DOT indicates activities related to a major commercialization challenge resulting in a twist in the process

a, $b$ Implementation of parallel strategies

$\longrightarrow$ Commercialization process ongoing/sustaining

- C.... Commercialization process ended

(Challenges) Commercialization challenges that accounted for the twist in the process 
Figure 4. Dynamic commercialization process model for RIs: from marketing strategy definition to making a profit in the market

$$
\begin{gathered}
\begin{array}{c}
\text { Technological } \\
\text { discontinuity } \\
\text { in the firm and } \\
\text { the market }
\end{array} \\
\text { Commercialization challenges shaping the process: }
\end{gathered}
$$

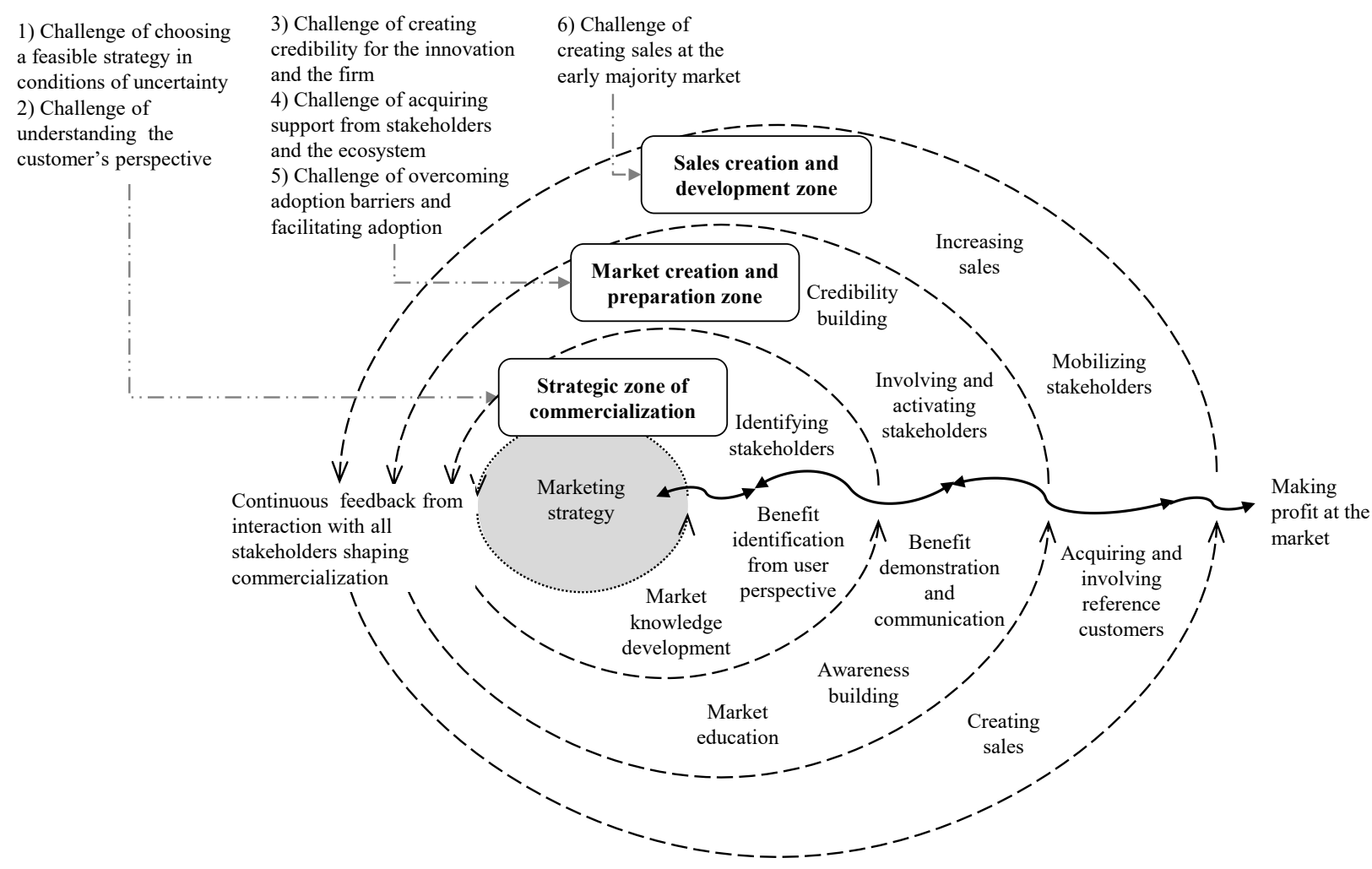


Table 1. The case and data sources

\begin{tabular}{|c|c|c|c|c|}
\hline Firm & Firm size & $\begin{array}{l}\text { Innovation } \\
\text { industry }\end{array}$ & Invention (year) & Primary and secondary data \\
\hline FirmBen & Large & $\begin{array}{l}\text { Functional } \\
\text { food }\end{array}$ & $\begin{array}{l}\text { Ingredient that } \\
\text { lowers cholesterol } \\
\text { (1989) }\end{array}$ & $\begin{array}{l}\text { Retrospective and real-time; } \\
\text { Archival data, 1995-2013; } 2 \text { interviews, 2010-2012 }\end{array}$ \\
\hline FirmEx & Medium & $\begin{array}{l}\text { Sports } \\
\text { equipment }\end{array}$ & $\begin{array}{l}\text { A walking pole } \\
\text { product and exercise } \\
(1995)\end{array}$ & $\begin{array}{l}\text { Retrospective; } \\
\text { Archival data and interview data base (comprising } 3 \\
\text { interviews), 1995-2012 }\end{array}$ \\
\hline FirmNT & Small & $\begin{array}{l}\text { Wellness } \\
\text { high-tech }\end{array}$ & $\begin{array}{l}\text { Monitor estimating } \\
\text { bone exercise }(2001- \\
2004)\end{array}$ & $\begin{array}{l}\text { Real-time; } \\
\text { Archival data, 2006-2012; } 7 \text { interviews, 2008-2010 }\end{array}$ \\
\hline FirmLG & Small & High-tech & $\begin{array}{l}\text { LED streetlight } \\
\text { technique }(2004- \\
2007)\end{array}$ & $\begin{array}{l}\text { Real-time; } \\
\text { Archival data, 2009-2013; } 6 \text { interviews, 2010-2013 }\end{array}$ \\
\hline FirmSF & Small & $\begin{array}{l}\text { Knowledge } \\
\text { intensive } \\
\text { business } \\
\text { service }\end{array}$ & $\begin{array}{l}\text { Productized } \\
\text { analytical system } \\
(2010)\end{array}$ & $\begin{array}{l}\text { Real-time; } \\
\text { Archival data, 2010-2013; } 5 \text { interviews, 2010-2013 }\end{array}$ \\
\hline FirmUni & Small & High-tech & $\begin{array}{l}\text { Communication } \\
\text { equipment (spin-off } \\
\text { 2010) }\end{array}$ & $\begin{array}{l}\text { Real-time; } \\
\text { Archival data, 2010-2013; } 3 \text { interviews, 2012-2013 }\end{array}$ \\
\hline
\end{tabular}


Table 2. Case synopses: how commercialization challenges shaped the commercialization processes

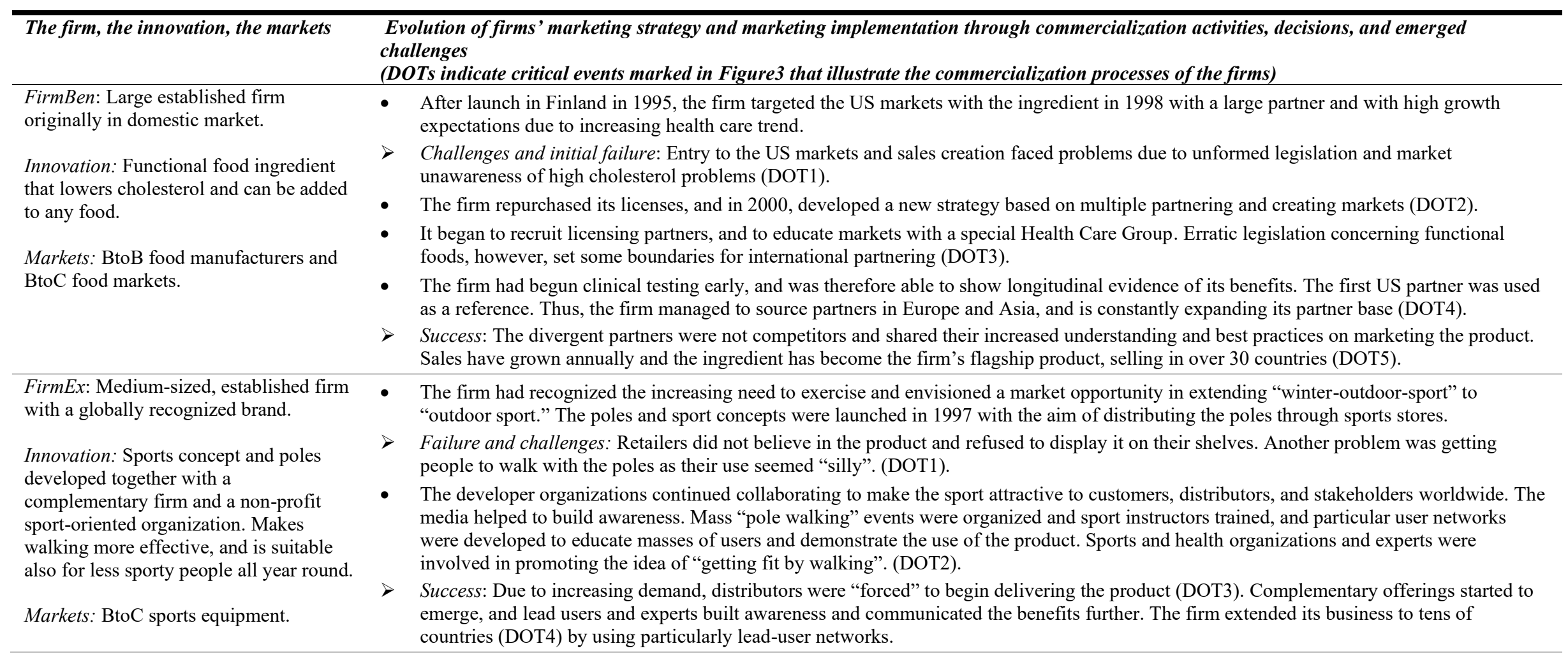


FirmNT: Small, new firm with several products.

Innovation High-tech wellness product: monitor that estimates sufficient exercise to maintain bone health and prevent osteoporosis.

Markets: BtoC wellness markets.

- The firm considered the monitor to have high market potential due to an increasing wellness trend and expanding risk and costs of osteoporotic diseases among females in industrial countries. The firm was pursuing huge profits and growth rates and targeted global consumer markets even though it only had experience in BtoB wellness markets. Design and marketing experts were employed in strategy development, market research, and later, the international launch.

- The firm put early effort into validating the credibility of the product and its benefits through award-winning scientific research. The firm believed that this would help to support adoption of the product and polish sales arguments (DOT1).

- Domestic launch was in 2005 (LINEa), and the media were very interested. The monitor was distributed through pharmacies, sports retailers, and an online shop. Parallel to the primary strategy, the firm negotiated with potential buyers of the technology and product (LINEb).

$>$ Challenges: The fundamental benefit of the monitor was not something for which the market was yearning. Despite interest in and moral support for the product, the sales creation failed both with consumers (DOT2a) and with firms (DOT2b).

- The product was launched in the UK at consumer markets. Large Japanese companies were very interested in the product, but first wanted to see some success in the domestic consumer market (DOT3b). To raise interest and awareness towards bone health issues in the market, the firm began to build up a closed network of firms with bone health-related products and services in 2007, the idea being that through collaboration they could fortify marketing of their bone health offerings (DOT3a)

$>$ Challenges and failure: Networking proved difficult for a small and unknown firm. Potential partners were supportive but not willing to commit to formal long-term collaboration to create bone health markets. The vague line between competition and collaboration complicated the situation, and the interaction ceased (DOT4a). Despite interest raised, the monitor did not break into consumer markets. After that, the firm focused on seeking a licensing partner/large buyer in 2008 (DOT4b), but failed.

FirmLG: Small firm with ten years' experience in consumer and BtoB LED products.

Innovation: LED technique and design for street lighting, offering high quality light and savings on energy and maintenance costs, meeting the standards for street lighting (unlike earlier competitors).

Markets: Particularly public sector (municipalities).
- The firm considered the LED street lights to have high global market potential since the sustainability trend and changing EU legislation pushed markets towards LED technology.

- To increase the market's overall awareness on the current state of LED technology and the firm's offerings, the technical manager had started early to actively lecture to experts in municipalities. After the product launch (2009), the firm acquired its first customers for the first, more general, version of the product, customer feedback for further development, and some revenue (DOT1).

- Challenges: Sales creation, however, faltered and the firm faced difficulties in making a profit with the innovation. Decision making and buying processes in municipalities were complex and it was difficult to identify buying decision makers, who varied from technical experts to politicians. The short-sighted interests of the risk and change-averse municipal decision makers did not resonate with the benefits of the innovation. Clients were keenly interested in the technology but less in buying the product. Customers were particularly suspicious of the new technique due to bad experiences with a competitor's earlier, but different, LED products. Technological experts' outdated knowledge increased mistrust towards the street light product, even though they trusted the firm's other products and expertise. (DOT2).

- The firm compared different business models. It also tried to generate partnerships offering broader lighting solutions that would lower the investment risk perceived by customers but with no success (DOT3). The firm employed their several business and technology awards in marketing, and also the testing and outdoor lighting cases. The sales argumentation was refined and the firm began employing sales agents (2012). Established contacts were utilized to find customers abroad. (DOT4). 
FirmSF: Small firm with ten years' experience on customized analysis services.

Innovation: An automated analysis service that accelerates analysis from months to hours, and decreases the need for personnel in customer firms. pharmaceutical services.
Markets: BtoB professional

- The firm pursued growth from global markets with their analysis service, which the firm considered offered remarkable improvements and benefits for divergent firms and organizations at pharmaceutical industries.

- The firm first employed external consultants and agents to induce international sales of the new service in 2010-2011 (DOT1).

$>$ Challenges: The agents' and consultants' sales activities did not deliver any new successful contacts. The contacted customers were initially interested, although suspicious (DOT2).

- The firm learned that they needed to contact targets themselves to express their expert status and service confidentiality. They employed their existing service customers as first references for the service (DOT3).

$>$ Challenges: Sales creation still failed. Customers were interested but the remarkable speed of the analysis raised questions concerning its trustworthiness; changes in analytical procedures were considered too risky in the conservative risk-avoiding pharmaceutical industries, and the potential cost-savings coming from the laboratory personnel reduction was not valued. (DOT4).

- Although customers were attracted to the new service, they ended up buying the traditional service instead. The firm re-modified its sales argumentation based on all feedback received: for example, in further sales presentations it diminished some benefits to increase credibility. The firm also considered increasing sales by out-licensing (DOT5).

$>$ Partial success and challenges: Even though the sales of the new service did not take off as intended, the innovation supported achieving the firm's strategic goals indirectly; it opened doors and was a successful sales tool to sell the "old" customized service.

FirmUni: Small, high-tech start-up spinoff.

- The device was first developed in a large company and then in the key project personnel's spin-off (2010). The product idea and market vision came partly from key managers' partners in South America and, therefore, the product was first targeted for fast-growing developing markets. These existing contacts were assumed to provide good access to potential end-users and to facilitate entering an established distribution network through mobile operators. Thereby, the firm assumed that sales would begin easily. The product was launched in 2012 (DOT1)

entertainment $3 \mathrm{G} / \mathrm{W}$-Fi-based product, enables the transfer of internet content to a TV screen, and the storage and sharing of mobile content.

Markets: BtoB (e.g., operators, hotels), BtoC (users). effort, or taking risks to create markets for it. This led to problems in creating awareness and getting the product onto the shelves (DOT2).
- Challenges: Distribution and complementary partners agreed on the product's market potential but were not interested in putting in the Also setting the price caused problems.

- The firm developed alternative strategies (DOT3)

- The firm began to contact potential partners in other developing areas (DOT4a), and spotted new use contexts in order to attain potential user and market segments. They began to negotiate with domestic retail chains and some web stores began to deliver the product (DOT4b) Awareness and credibility of the firm were supported by international design and innovation awards.

$>$ Challenges and partial success: The firm managed to secure some sales in both developing and domestic markets, but found it hard and slow to generate sales (DOT5). To date, it has gained its first large customer from Arabic markets and consequently it has made strategic remodifications again (DOT6) and is now targeting hotels, private hospitals, and shopping malls in these markets (DOT7). 
